\title{
A note on "An alternative multiple attribute decision making methodology for solving optimal facility layout design selection problems”
}

\section{R. Venkata Rao}

Department of Mechanical Engineering, S.V. National Institute of Technology, Ichchanath, Surat, Gujarat-395 007, India

\begin{tabular}{|c|c|}
\hline A R T I C L E I N F O & AB S T RAC T \\
\hline $\begin{array}{l}\text { Article history: } \\
\text { Received } 25 \text { November } 2011 \\
\text { Accepted } 11 \text { January } 2011 \\
\text { Available online } \\
\text { 12 January } 2012 \\
\text { Keywords: } \\
\text { Facility layout design } \\
\text { Multiple attribute decision making } \\
\text { Preference selection index }\end{array}$ & $\begin{array}{l}\text { A paper published by Maniya and Bhatt (2011) (An alternative multiple attribute decision } \\
\text { making methodology for solving optimal facility layout design selection problems, Computers } \\
\& \text { Industrial Engineering, 61, 542-549) proposed an alternative multiple attribute decision } \\
\text { making method named as "Preference Selection Index (PSI) method" for selection of an } \\
\text { optimal facility layout design. The authors had claimed that the method was logical and more } \\
\text { appropriate and the method gives directly the optimal solution without assigning the relative } \\
\text { importance between the facility layout design selection attributes. This note discusses the } \\
\text { mathematical validity and the shortcomings of the PSI method. }\end{array}$ \\
\hline
\end{tabular}

(C) 2012 Growing Science Ltd. All rights reserved

\section{Introduction}

Selection of an optimal facility layout design is an iterative process as it relates to the interrelationship between various departments of the organization. So the decision maker must be creative and comprehensive while selecting the optimal layout and the industrialists or decision makers always face the difficulties in selecting an optimal facility layout design. Recently, Maniya and Bhatt (2011) proposed an alternative decision making method named as 'Preference Selection Index (PSI) method' and they had considered two facility layout design selection problems for demonstration.

The authors had concluded that the method is simple, logical and more appropriate for the facility layout design selection problems as compared to the methods presented by the previous researchers. Furthermore, the authors had claimed that the main benefit of the PSI method is that there is no need to assign relative importance between the attributes and it is not required to compute weights of attributes involved in the decision making problems. The main aim of this note is to discuss the mathematical validity and the merits of the method proposed by Maniya and Bhatt (2011) as compared to the other multiple attribute decision making (MADM) methods.

\footnotetext{
* Corresponding author. Tel.: +91-2612201982; Fax: 91-2612227334

E-mail: ravipudirao@gmail.com (R. V. Rao)

(c) 2012 Growing Science Ltd. All rights reserved. doi: $10.5267 /$ j.ijiec.2012.01.002
} 


\section{Discussion on the PSI method}

The PSI method described by Maniya and Bhatt (2011) was applied previously by them for material selection in Maniya and Bhatt (2010). The normalization procedure described by Eqs. (1) and (2) in step-5 of their paper was already suggested by Rao (2007) who had implemented this type of normalization for various decision making situations of the manufacturing environment and compiled the approaches of previous researchers. Maniya and Bhatt (2011) had calculated the preference variation value for each attribute $\left(\prod_{j}\right)$ in step-7 of their paper by using Eq. (4).

In their previous paper, Maniya and Bhatt (2010) had mentioned that this preference variation value is based on the concept of 'sample variance' analogy. The variance and the standard deviation (i.e. square root of the variance) are statistics that measure how widely spread the values in a dataset are. If the data points are all close to the mean, then the sample variance and the sample standard deviation are close to zero. If many data points are far from the mean, then the sample variance and the sample standard deviation are far from zero. If all the data values are equal, then the sample variance and the sample standard deviation are both zero.

The Eq. (4) proposed by Maniya and Bhatt (2011) in their paper doesn't indicate the 'sample variance' concept, as the variance should actually be expressed by the following Eq. (1).

$$
\prod_{j}=\left\{\sum_{i=1}^{n}\left[N_{i j}-\bar{N}\right]^{2}\right\} / n,
$$

where, $N_{i j}$ is the normalized value of the $j^{\text {th }}$ attribute corresponding to the $i^{\text {th }}$ alternative, ' $n$ ' is the number of alternatives and $\bar{N}$ is the mean value of the normalized data of the $j^{\text {th }}$ attribute. As Maniya and Bhatt (2011) had mentioned about the 'sample variance', Eq. (1) of this paper can be used for calculating the variance. The use of Eq. (4) by Maniya and Bhatt (2011) in their paper for calculating the 'sample variance' is improper and the term $(1 / n)$ was missing in the calculation of 'sample variance' by them. In fact, Eq. (4) proposed by them for calculating the preference variation value $\left(\prod_{j}\right)$ does not indicate the 'sample variance' but it actually indicates the 'squared' Euclidean distance between the normalized value $N_{i j}$ of the $j^{\text {th }}$ attribute corresponding to the $i^{\text {th }}$ alternative and the mean of normalized values of $j^{\text {th }}$ attribute. If the authors wished to calculate this Euclidean distance from the mean, then the square root of the value given by Eq. (4) of this paper should have been used to indicate the distance and this value of Euclidean distance should have been used subsequently. But Maniya and Bhatt (2011) had not done so. The mathematical validity of the use of Eq. (5) of their paper which indicates the "deviation in preference value" is highly questionable and is not justified and as a consequence of this, the Eq. (6) is also not justified.

In fact, even though Maniya and Bhatt (2011) had not mentioned specifically, the Steps-7, 8 and 9 proposed by them are actually meant for calculating the objective weights of importance of the attributes. Various methods for finding the weights of importance of the attributes can be found in the literature and most of them can be categorized into two groups: (i) methods to find subjective weights and (ii) methods to find objective weights. Subjective weights are determined according to the preferences of the decision maker and certain methods like AHP method (Saaty, 2000), weighted least squares method (Chu et al., 1979), Delphi method (Hwang and Lin, 1987), and Edwards and Newman method (1982) belong to this category of methods.

The methods to determine the objective weights of the attributes use the attributes' data for various alternatives without any consideration of the decision maker's preferences and certain methods like Shannon's entropy method (Shannon, 1948; Deng et al., 2000), standard deviation method (Diakoulaki et al., 1995; Deng et al., 2000), multiple objective programming (Choo and Wedley, 
1985), and principal element analysis (Fan, 1996) belong to this category of methods. Since in the most real problems, the decision maker's expertise and judgment should be taken into account, subjective weighting is preferable, but when obtaining such reliable subjective weights is difficult, the use of objective weights may be useful. Use of subjective weights, objective weights and the integrated weights (i.e. considering both the subjective and objective weights) had been attempted recently in Rao and Patel (2010) and Rao et al. (2011).

Maniya and Bhatt (2011) had mentioned that the 'benefit' of their method is that it gives 'directly' the optimal solution without assigning the relative importance between facility layout design selection attributes. The authors had not used the word 'weights of the attributes' in their paper and gave the impression that the weights of the attributes are not needed by the PSI method. In fact, the steps-7, 8 and 9 of the PSI method proposed by them for calculating the values of preference variation $\left(\prod_{j}\right)$ and the overall preference $(\Psi j)$ are nothing but the steps used for calculating the objective weights of the attributes.

It may be said that the authors had used the 'sample variance' analogy for calculating the objective weights. However, as mentioned above, the authors had mistaken the squared Euclidean distance as the 'sample variance' and incorrectly calculated the value of $\Phi j$. The method of sample variance (which is given by Eq. (1) of this paper) or standard deviation (which is a square root of Eq. (1) of this paper) should have been used by the authors for calculating the objective weights of the attributes if they were interested to use the 'sample variance' analogy. The standard deviation method of obtaining the objective weights of the attributes is already an established method (Diakoulaki et al., 1995; Deng et al., 2000).

An important point is that the Eq. (5) of their paper for calculating the "deviation in preference value" for each attribute should not be used when standard deviation method is used and the objective weights of the attributes can be calculated directly by the following Eq. (Diakoulaki et al., 1995; Deng et al., 2000).

$$
w_{j}=\sigma_{j} / \sum_{j=1}^{m} \sigma_{j},
$$

where, $w_{j}$ is the weight of the $\mathrm{j}^{\text {th }}$ attribute and $\sigma_{j}$ is the standard deviation of the $\mathrm{j}^{\text {th }}$ attribute.

It may be mentioned here that finding the appropriate weight for each attribute is one of the main points in any MADM problem. Since in the most real problems, the decision maker's expertise and judgment should be taken into account, subjective weighting is preferable and the PSI method proposed by Maniya and Bhatt (2011) doesn't make any provision for the preferences of the decision maker in assigning the relative importance relations and obtaining the attributes weights thereby.

Another important point is that Maniya and Bhatt (2011) had not suggested specifically in their proposed PSI methodology about "how to deal" with the fuzzy attribute data, i.e. qualitative attributes. The two examples presented by them are containing only the quantitative attributes. Rao (2007) and Rao et al. $(2010,2011)$ had used a 11-point fuzzy conversion scale to convert a qualitative attribute into a quantitative attribute.

No such scales were suggested by Maniya and Bhatt (2011) in their PSI method for conversion of a qualitative attribute into a quantitative one. Furthermore, the claim of the authors that there no need to perform any type of the sensitivity analysis does not find much meaning as there is no scope in PSI method to see how the changes in the weights of importance of the attributes affect the decision making process. In fact, the PSI method proposed by the authors calculates only the objective weights of the attributes and there is no provision to carry on the sensitivity analysis which is required in any MADM problem. 


\section{Discussion on the examples considered for demonstration and validation}

Maniya and Bhatt (2011) presented two examples for demonstration and validation of their PSI method. These examples are described below.

\subsection{Example 1}

Maniya and Bhatt (2011) presented a problem for evaluation and selection of optimal facility layout design that was previously attempted by Chakraborty and Banik (2007). This problem contained 10 facility layout design alternatives and 6 attributes. The ranking of the alternative facility layout designs in the descending order of the selection index suggested by Maniya and Bhatt (2011) was: 27-4-10-1-9-3-5-8-6 and the rankings suggested by Chakraborty and Banik (2007) was: 2-1-6-9-10-74-5-8-3. It is required to be mentioned here that the objective weights of importance of the attributes (i.e. "deviations in preference values") used by Maniya and Bhatt (2011) were: $w_{1}=0.1089, w_{2}=$ $0.1965, w_{3}=0.0231, w_{4}=0.1295, w_{5}=0.5894$, and $w_{6}=0.0546$ and these weights were completely different from the weights used by Chakraborty and Banik (2007) obtained by the application of analytical hierarchy process (AHP) method.

It is quite obvious that the comparison of results of two methods is meaningful only when the same weights of importance of the attributes are considered. If the weights considered by two different researchers are different for the same decision making problem, then there is possibility that the rankings obtained of the alternatives will be different (of course, some rankings may match, by chance, as it happened in this example with the ranks of three alternatives 2, 5 and 8 matching in both the methods). The Spearman's rank correlation coefficient between the rankings given by the PSI method proposed by Maniya and Bhatt (2011) and the AHP method used by Chakraborty and Banik (2007) is 0.1757 which clearly shows that there are many differences in the rankings of alternatives given by the two methods and the ranks obtained by these two methods should not be compared. Also, the "demerits" of using the AHP as mentioned by Maniya and Bhatt (2011) are not correct at the present level of research and these issues were already addressed in Rao (2007).

\subsection{Example 2}

This example problem contained 18 facility layout design alternatives and 6 attributes and was previously attempted by Yang and Kuo (2003) using AHP and data envelopment analysis (DEA) methods, Yang and Hung (2007) using TOPSIS and fuzzy TOPSIS methods, and Kuo et al. (2008) using GRA method. Here also, Maniya and Bhatt (2011) had used objective weights of importance of the attributes to calculate the facility layout design selection index. The weights considered by Maniya and Bhatt (2011) were completely different from the weights used by other researchers and the comparison between the rankings given by different methods should not be made.

So far as the calculations are concerned, a close look at the PSI method reveals that this method also involves considerable number of calculations while carrying out the methodology described in steps5 to 10 of the methodology proposed by the authors. In reality, whatever be the MADM method adopted, the calculations becomes complex as the size of the decision making problem increases and PSI method is no exception. The 'statistics' used by Maniya and Bhatt (2011) is questionable and mathematically flawed as explained in Section 2. Furthermore, the authors had not considered the issues such as representing the qualitative attributes, sensitivity analysis, rank reversals, etc. while proposing the method. 


\section{Conclusions}

From the discussions presented in Sections 2 and 3, it may be concluded that the PSI method proposed by Maniya and Bhatt (2011) is not exactly a logical alternative MADM method. The 'sample variance' analogy proposed by Maniya and Bhatt (2011) does not have enough mathematical validity. The authors had mentioned that the 'benefit' of the method is that the method directly gives optimal solution without assigning the relative importance between facility layout design selection attributes. However, the method proposed by them uses only the objective weights of the attributes and doesn't consider the preferences of the decision maker. In most of the real decision making problems, the decision maker's expertise and judgment should be taken into account and subjective weighting may be preferable. Furthermore, the authors had not considered the logic that the comparison of two MADM methods for a decision making problem becomes meaningful only when the same weights of attributes are used by both the methods.

No specific steps were suggested in the PSI method to deal with the qualitative attributes and there is no provision to carry out the sensitivity analysis. The claim made by the authors that the PSI method gives results with minimum and simple calculations is also not correct as the complexity of calculations increases with the size of the decision making problem and the PSI method is no exception. Thus, the statements made by the authors are not well justified.

\section{References}

Chakraborty, S., \& Banik, B. (2007). An analytic hierarchy process (AHP) based approach for optimal facility layout design. IE(I) Journal-PR, 88, 12-18.

Chen, S.J., \& Hwang, C.L. (1982). Fuzzy multiple attribute decision making methods and applications. Lecture notes in economics and mathematical systems. Berlin: Springer-Verlag. Choo, E.U., \& Wedley, W.C. (1985). Optimal criterion weights in repetitive multicriteria decision making. Journal of Operational Research Society, 36(11), 983-992.

Chu, A.T.W., Kalaba, R.E., \& Spingarn, K. (1979). A comparison of two methods for determining the weights of belonging to fuzzy sets. Journal of Optimization Theory and Applications, 27(4), 531-538.

Deng, H., Yeh, C.H., \& Willis, R.J. (2000). Inter-company comparison using modified TOPSIS with objective weights. Computers \& Operations Research, 27(10), 963-973.

Diakoulaki, D., Mavrotas, G., \& Papayannakis, L. (1995). Determining objective weights in multiple criteria problems: the CRITIC method. Computers \& Operations Research, 22(7), 763-770.

Edwards, W., \& Newman, J.R. (1982). Multiattribute evaluation. California: Sage Publications.

Fan, Z.P. (1996). Complicated multiple attribute decision making: Theory and applications. Ph.D Dissertation, Northeastern University, Shenyang, China.

Hwang, C.L., \& Lin, M.J. (1987). Group decision making under multiple criteria: Methods and applications. Berlin: Springer-Verlag.

Kuo, Y., Yang, T., \& Huang, Gaun-Wei (2008). The use of grey relational analysis in solving multiple attribute decision making problems. Computers \& Industrial Engineering, 55, 80-93.

Maniya, K., \& Bhatt, M. G. (2010). A selection of material using a novel type decision-making method: Preference selection index method. Materials and Design, 31(4), 1785-1789.

Maniya, K., \& Bhatt, M. G. (2011). An alternative multiple attribute decision making methodology for solving optimal facility layout design selection problems. Computers \& Industrial Engineering, 61, 542-549.

Rao, R.V. (2007). Decision making in the manufacturing environment using graph theory and fuzzy multiple attribute decision making methods. London: Springer-Verlag.

Rao, R. V., \& Patel, B.K. (2010). Subjective and objective integrated multiple attribute decision making method for material selection. Materials and Design, 31(10), 4738-4747. 
Rao, R. V., Patel, B.K., \& Parnichkun, M. (2011). Industrial robot selection using a novel decision making method. Robotics \& Autonomous Systems, 59(6), 367-375.

Saaty, T.L. (2000). Fundamentals of decision making and priority theory with the AHP. Pittsburg: RWS Publications.

Shannon, C.E. (1948). A mathematical theory of communication. Bell Systems and Technology Journal, 27, 379-423.

Yang, T., \& Hung, C. (2007). Multiple-attribute decision making methods for plant layout design problem. Robotics and Computer-Integrated Manufacturing, 23, 126-137.

Yang, T., \& Kuo, C. (2003). A hierarchical AHP/DEA methodology for the facilities layout design problem. European Journal of Operational Research, 147, 128-136. 